\title{
LA PARTICIPACIÓN COMO RESPUESTA A LA CRISIS DE LA REPRESENTACIÓN: EL ROL DE LA DEMOCRACIA PARTICIPATIVA
}

ALFREDO RAMÍREZ NÁRDIZ 
SUMARIO

I. BREVE APROXIMACIÓN AL CONCEPTO DE LA CRISIS DE LA REPRESENTACIÓN: 1. Origen de la cuestión; 2. Planteamientos actuales: la crítica generalizada a los partidos políticos. II. EL ROL DE LA DEMOCRACIA PARTICIPATIVA: 1. ¿Qué es la democracia participativa?; 2. La democracia participativa como respuesta a la crisis de la representación. III. CONCLUSIONES. IV. BIBLIOGRAFÍA. VI. JURISPRUDENCIA. VII. PÁGINAS WEB. 


\title{
LA PARTICIPACIÓN COMO RESPUESTA A LA CRISIS DE LA REPRESENTACIÓN: EL ROL DE LA DEMOCRACIA PARTICIPATIVA
}

\author{
ALFREDO RAMÍREZ NÁRDIZ \\ Profesor Contratado Doctor, Facultad de Derecho \\ Universidad Libre, Seccional Barranquilla ${ }^{1}$
}

\section{BREVE APROXIMACIÓN AL CONCEPTO DE LA CRISIS DE LA REPRESENTACIÓN}

No es objeto de estas páginas desarrollar un concepto, por otra parte sobradamente estudiado y analizado ${ }^{2}$, como es la crisis de la representación. No obstante, de cara a plantear el posible rol que la democracia participativa puede desarrollar en la corrección o en la contribución a la corrección de algunos de sus efectos, resulta de gran relevancia hacer una breve y sucinta referencia a la problemática que la crisis de la representación supone, prestando especial atención al carácter que la misma ha cobrado en los últimos tiempos.

${ }^{1}$ Este artículo es producto del proyecto de investigación «Transformaciones democráticas y democracia participativa» perteneciente al grupo de investigación «Poder público y ciudadanía» de la Universidad Libre, Seccional Barranquilla, km. 7. Antigua vía a Puerto Colombia. A. A. 1752, Barranquilla, Colombia.

aramirez@unilibrebaq.edu.co

${ }^{2}$ Indica, en este sentido, De Vega que «nada tiene de particular, por lo tanto, que por doquier se hable de una crisis generalizada de la representación (FRANCOIS D'ARCY, HANNA FENICHEL, FISICHELLA, etcétera).» VEGA, P. de, (1993): «La crisis de la representación política en la democracia de partidos», Tendencias contemporáneas del Derecho electoral en el mundo, México, Cámara de Diputados, pp. 202-203. 


\section{Origen de la cuestión}

Como indica Fernández-Miranda Campoamor, la crisis de la representación, la crisis del mandato representativo y la crisis del parlamentarismo son, en realidad, como ideas recurrentes, tan antiguas como la misma formulación clásica de la teoría liberal de la representación o la consolidación de la forma de gobierno parlamentario. La consideración de que la representación y el parlamentarismo se encuentran en crisis es una idea tan habitual que, más que probablemente, lo que late detrás de ella no es tanto una crisis determinada, sino una sucesión de problemas que a lo largo del tiempo han ido surgiendo y a los cuales se ha enfrentado el hecho representativo y el gobierno parlamentario ${ }^{3}$.

La crisis de la representación se plantea tan pronto como se contrapone el esquema original e ideal del parlamentarismo representativo, que concibe al parlamento como sede del debate racional en el que se busca y encuentra la verdad a través del intercambio de ideas entre hombres sabios y buenos que elaboran las leyes como manifestaciones de la soberanía nacional materializada en la voluntad única y uniforme a la que ellos dan vida ${ }^{4}$, con la realidad pronto contrastada del parlamento como teatro de la lucha entre los distintos intereses sociales contrapuestos defendidos por diferentes facciones o partidos que, más allá de un hipotético bien común, buscan la satisfacción de los deseos particulares del grupo o grupos sociales, partido o partidos, a los que representan ${ }^{5}$. Esta dicotomía entre teoría y realidad se manifiesta en diversas disfunciones en el esquema representativo. Destaca la producida alrededor del rol del representante, que en la teoría se concibe como un sujeto libre de cualquier tipo de mandato imperativo o control externo y que se relaciona directamente con sus representados, pero que en la práctica depende y obedece al partido en el seno del cual

3 FERNÁNDEZ-MIRANDA CAMPOAMOR, C. y FERNÁNDEZ-MIRANDA CAMPOAMOR, A., (2003): Sistema electoral, partidos politicos y parlamento, Madrid, Colex, pp. 37-38.

${ }^{4}$ Debiendo ser el parlamento, como indica GARZÓN VALDÉS haciendo referencia a BURKE, «el foro donde, a través de la discusión pública, de la deliberación racional, es posible descubrir la verdad. Esta coincide con el interés nacional que, cuando es satisfecho, aprovecha también a cada miembro de la comunidad» GARZÓN VALDÉS, E. (1989): «Representación y Democracia», Doxa: Cuadernos de Filosofía del Derecho, Universidad de Alicante, n. ${ }^{\circ}$ 6, p. 144.

5 «Hoy el problema más crítico que afecta a la democracia está conectado con la representación política, es decir, con el Parlamento. La actual erosión de la legitimidad parlamentaria con el consiguiente distanciamiento entre representantes y representados es consecuencia de muy diversos factores, pero entre ellos y principalmente de los excesos del llamado "Estado de partidos" y de los defectos del control parlamentario del Gobierno.» ARAGÓN REYES, M. (1996): «Parlamentarismo y antiparlamentarismo en el primer tercio del siglo xx: la proyección actual de aquella polémica», Revista de Estudios Políticos, n. ${ }^{\circ}$ 93, julio-septiembre, p. 63. 
se ha presentado a la elección popular, priorizando en su actuar los objetivos políticos de ese partido sobre el interés general que ha de verse satisfecho en el modelo parlamentario representativo ideal y actuando como un delegado del partido sin verdadera voluntad propia. Se deshace así la estructura representativa original quebrando la relación entre representante y representado y surgiendo una nueva y verdadera relación entre votante y partido político ${ }^{6}$.

Pero la disciplina de grupo o partido a la cual se someten los representantes a modo de nuevo modelo de mandato imperativo no es, ni mucho menos, el único problema que la práctica de la representación política genera y en la que se materializa la quiebra entre el esquema teórico y la realidad práctica del modelo representativo. Como se indicaba anteriormente, la crisis de la representación acaba por asociarse a multitud de fenómenos que sucesivamente surgen alrededor de la práctica política en el seno de la democracia representativa y que se manifiestan como disfunciones o vicios del modelo: la pérdida de centralidad del parlamento, la politización de las instituciones y su monopolización por los partidos políticos (particularmente la Justicia) ${ }^{7}$, etc. Así, la crisis de la representación acaba por ser, o al menos por verse, más allá de como un fenómeno o circunstancia concreto, como un todo general alrededor del cual se enmarcan todas las críticas, los problemas y los malos funcionamientos de la democracia representativa, así como las reflexiones, dudas y temores sobre el Estado mismo ${ }^{8}$.

\section{Planteamientos actuales: la crítica generalizada a los partidos políticos}

De las anteriores líneas ya es posible extraer que la llamada crisis de la representación se ve en gran medida protagonizada en el presente por la crítica al rol

6 «(...) la relación electoral real no se produzca en los términos en que debería producirse, esto es, entre representante y representado, sino entre electores y partidos (...)»VEGA, P. de (1993): op. cit, p. 195.

7 «Para Asensi, es innegable que en el presente se produce una crítica a la democracia representativa, la cual es una crítica generalizada de los mecanismos representativos tradicionales, en particular del Parlamento y de los partidos políticos.» RAMÍREZ NÁRDIZ, A. (2010): Democracia Participativa. La Democracia Participativa como profundización en la Democracia, Valencia, Tirant lo Blanch, p. 118, citando a ASENSI SABATER, J. (1998): La época constitucional, Tirant lo Blanch, Valencia, pp. 197 y ss.

8 «La crisis de la representación y los vacíos de legitimidad política que esa crisis provoca, terminan generando una crisis aún más alarmante y de mayor envergadura como es la crisis del mismo concepto de Estado.» VEGA, P. de, (1998): Legitimidad y representación en la crisis de la democracia actual, Barcelona, Colección Working Papers, N. ${ }^{\circ} 141$, Institut de Ciències Polítiques i Socials, p. 25. 
de los partidos políticos 9 . Si bien la actitud hacia los partidos políticos ha vivido distintas fases desde la aparición de los mismos en la vida pública de las naciones ${ }^{10}$, resulta innegable que en la actualidad son vistos por no pocos autores no como sujetos políticos intermedios necesarios para la configuración y organización de la voluntad general o, como dice el artículo 6 de la CE «instrumento fundamental para la participación política», sino como organizaciones debatidas y criticadas. La crítica a los partidos políticos, particularmente en los últimos tiempos, es en muchas ocasiones muy agresiva y se les acusa de prácticamente cualquier mal o problema que sufra o pueda sufrir en el presente o en el futuro próximo la democracia representativa. Para sus críticos, los partidos políticos acuden a la ciudadanía únicamente para satisfacer y defender sus intereses y privilegios particulares $^{11}$ de grupo —o incluso clase $\mathrm{e}^{12} \mathrm{o}$ casta $^{13}$ — , sino directamente para que

9 «El eslabón roto es el partido político, en la medida que produce los siguientes efectos, entre otros: introducir una nueva mediación entre el gobernante-legislador y los titulares de la potestad legislativa, despersonalizar el sufragio, desvirtuar su contenido esencial mediante leyes electorales inconstitucionales, apropiarse del proceso electoral, administrar sin control los resultados del mismo, actuar internamente lesionando la democracia y financiarse ilegalmente, incluyendo parte de lo presupuestado para los representantes.» ACOSTA SÁNCHEZ, J. (1994): «La articulación entre representación, Constitución y democracia: Génesis, crisis actual y Constitución española», Revista de Estudios Políticos, n. ${ }^{\circ}$ 86, pp. 150-151.

${ }^{10}$ En este sentido es de gran interés el resumen que hace Fernández-Miranda Campoamor de las distintas fases o posturas que el Estado ha mantenido hacia los partidos políticos citando tanto la exposición de Triepel como la de Pérez Royo. Para el primero el Estado liberal parte de una inicial hostilidad hacia los partidos políticos — a los que considera facciones - al considerar que entre ciudadano y Estado no debe haber sujeto intermedio alguno; continúa con una segunda fase de indiferencia; una tercera fase de aceptación que asume la importancia de los partidos políticos y los reconoce legalmente; y termina integrándolos en el sistema y considerándolos un elemento esencial del Estado democrático. Por su parte, para Pérez Royo hay tres momentos: uno inicial en el que se considera a los partidos políticos como un mal absoluto, pues nada debe interponerse entre los ciudadanos y el Estado - menos aun los partidos, que son vistos como facciones o pandillas-; una segunda fase donde los partidos son vistos como un bien deseable; y una tercera fase donde se les tiene como un mal necesario para el funcionamiento del Estado democrático. FERNÁNDEZ-MIRANDA CAMPOAMOR, C. y FERNÁNDEZ-MIRANDA CAMPOAMOR, A., (2003): op. cit., pp. 38-42.

${ }^{11}$ Unos políticos que son vistos «más como un grupo que defiende sus propios intereses que como un conjunto de personas al servicio de la comunidad.» ARAGÓN REYES, M. (1996): op. cit., p. 66.

12 «las demandas democráticas más llamativas hoy en nuestra sociedad: personalización e individualización de las responsabilidades públicas, disolución de la "clase política” (...)» ACOSTA SÁNCHEZ, J. (1994): op. cit., p. 150.

${ }^{13}$ En esta línea se posicionan textos como La casta: El increíble chollo de ser político en España de MONTERO (2009). 
sus miembros se enriquezcan a título personal ${ }^{14}$; reducen a la ciudadanía a masa ${ }^{15}$; rebajan el discurso político a consignas sin contenido ${ }^{16}$; se apropian de las instituciones $^{17} \mathrm{y}$, en particular, del poder judicial al que politizan y degradan, etc. Cualquier crisis económica coyuntural acentúa estas críticas al existir la tendencia de la ciudadanía a considerar a los partidos políticos y a los políticos en general como importantes responsables de la misma, pero las críticas citadas están, en cualquier caso y crisis al margen, cada vez más asentadas en un imaginario colectivo en el que con fuerza se plantea la necesidad de reformar los partidos políti$\cos ^{18}$, llegándose a considerar, incluso, que el mayor peligro que amenaza a la democracia no viene de fuera, sino que habita en la desafección que los partidos políticos causan en los ciudadanos para con ella ${ }^{19}$, así como, en el propio actuar viciado de dichos partidos políticos. Indica de Vega, sin embargo que

«constituiría una distorsión radical de la realidad y de la historia el inculpar a los partidos de la destrucción de los esquemas jurídicos y políticos sobre los que se edificó la estructura del Estado liberal. Dicho con toda contundencia,

14 Así, desde este punto de vista, la política «no tendría otro objetivo que su propio poder y a veces, incluso, el enriquecimiento personal de sus miembros» TOURAINE, A. (1994): op. cit., pp. 22-23.

${ }^{15}$ Los partidos políticos no van «a la esfera pública a otra cosa que a extraer de él lealtad de una población reducida a masa», HABERMAS, J. (1998): Facticidad y validez. Sobre el derecho y el Estado democrático de derecho en términos de teoría del discurso, Madrid, Trotta. p. 460.

16 «(...) la adaptación escandalosa de la propaganda política a los más estrictos moldes de las técnicas publicitarias del mercado, termina convirtiendo la representación en un simple mecanismo de selección de líderes con connotaciones carismáticas en el que las valoraciones políticas sencillamente desaparecen.» VEGA, P. de, (1998): op. cit. p. 25.

17 «La democracia se corrompe y está desorientada (...) cuando el sistema político invade la sociedad civil y el Estado (...) en la actualidad en los países considerados democráticos, ese es el primer peligro, el reino de los partidos (...)» TOURAINE, A. (1994): ¿Qué es la Democracia?, Madrid, Temas de Hoy, pp. 22-23.

18 «Hay que reformarlos, transformarlos, lo que significa hablar del sistema electoral, de la transparencia, de la regulación de los intereses, incompatibilidades y protocolos de actuación, financiación, controles rigurosos y rendición de cuentas, responsabilidades internas y externas, y un largo etcétera. Pero la cuestión central, que ya debería estar zumbando en los oídos de las cúpulas partidarias, es que la forma-partido, un viejo modelo del siglo XIX, hipertrofiado en el Xx, toca a su fin. Los partidos jerárquicos, oligárquicos y demasiado entrometidos en la gobernanza, hasta el punto de controlar todos los resortes del poder hasta sus más finas ramificaciones, al margen de su inoperancia, son propicios a la corrupción y a la elusión de responsabilidades» ASENSI SABATER, J. (2013): «Partidos en la picota», Diario Información de Alicante, 21 de enero.

19 «La independencia creciente de los partidos políticos respecto a las fuerzas sociales» conduce a que muchos ciudadanos se enfrenten a «una sociedad en la que ya no se sienten participar por razones económicas, políticas, étnicas o culturales.» TOURAINE, A. (1994): op. cit., pp. 122-123. 
no son los partidos los que aniquilan la noción de representación clásica, sino que es la crisis anterior y más profunda de los supuestos en los que esa noción se fundamentaba, la que determina la presencia de los partidos. Por ello, lejos de contemplar al Estado de partidos como el gran causante de la destrucción del orden jurídico político liberal clásico, acaso tengamos que empezar a entenderlo como la manifestación más fehaciente y la consecuencia más clara de las contradicciones internas de un sistema llamado históricamente a periclitar (...) Ahora bien, que los partidos políticos no sean causantes ni culpables de la destrucción del orden liberal, sino una mera consecuencia de esa destrucción, no significa que su actuación política deje de ser por ello un elemento decisivo que colabora a la aceleración de la crisis, y el epifenómeno más significativo y gráfico en que la propia crisis se manifiesta (...) la experiencia nos enseña que cuando los partidos desaparecen, los que les sustituyen son los grupos de presión, los magnates de las finanzas o los demagogos con vocación de dictadores.» ${ }^{20}$.

En cualquier caso, en los últimos años, y acentuado por el fenómeno de la crisis económica, la visión negativa de los partidos políticos y, en gran medida, de la democracia representativa como el todo del que ellos son los principales actores prácticos, se ha extendido a grandes grupos poblacionales y, así, aparecen estudios de opinión en los que la política y los políticos son considerados como uno de los grandes problemas de los ciudadanos ${ }^{21}$ y se asiste a la aparición de sucesivos «movimientos ciudadanos» que reclaman mediante movilizaciones en las calles cambios en el modelo democrático. Cambios caracterizados por una petición general de regeneración y profundización en la democracia ${ }^{22}$.

${ }^{20}$ VEGA, P. de, (1998): op. cit., pp. 15-19.

${ }^{21}$ Especialmente llamativo fue el barómetro de noviembre de 2012, estudio n. ${ }^{\circ} 2966$, sobre los mayores problemas de los españoles, en el que el CIS situó a «los políticos, los partidos políticos y la política en general» como el tercer mayor problema de los españoles sólo superado por el desempleo y la crisis económica. Un año después, el barómetro del CIS de noviembre de 2013 , estudio n. ${ }^{\circ} 3005$, mantenía a los políticos, los partidos políticos y la política en general como cuarto problema de los españoles, superado de nuevo por el desempleo y los problemas de índole económica y adelantado por la corrupción. CIS (2012): Barómetro de noviembre 2012, Estudio n." 2966, cis.es, consultado el 17/01/2013 y CIS (2013): Barómetro de noviembre de 2013, Estudio n. 3005, cis.es, consultado el 02/02/2014.

22 Paradigmático de estos movimientos es el español 15M, el cual se caracteriza, entre otros, por los siguientes elementos (extraídos de sus webs): desencanto con el modelo político actual y, en particular, con los partidos políticos y los políticos profesionales; rechazo del sistema económico capitalista, especialmente del capitalismo financiero; solicitud de mayor participación ciudadana y de mayor control de los ciudadanos sobre sus representantes; solicitud de profundización y mejora de la democracia; etc. Para ver en detalle todos estos elementos aquí sintetizados se recomienda consultar la web de «¡Democracia Real: YA!» (democraciarealya.es) y el blog del «Movimiento 15M» (movimiento15m.org). Aun y lo plural de sus miembros, de sus demandas 


\section{EL ROL DE LA DEMOCRACIA PARTICIPATIVA}

Siendo este el escenario en el que se enmarca en el presente la crisis de la representación, cabe plantearse si la situación descrita puede verse mejorada o aminorada en su problemática merced al papel de la democracia participativa, acercando, mediante los instrumentos participativos que la componen, a los ciudadanos a la toma de decisiones sobre su gobierno y permitiéndoles tener un mayor control sobre sus representantes, mejorando así la relación de confianza entre gobernantes y gobernados y fortaleciendo la democracia ante posibles procesos degenerativos.

\section{1. ¿Qué es la democracia participativa?}

Una definición de la democracia participativa podría ser la siguiente:

«conjunto de instrumentos jurídicos (referendos, iniciativas populares, etc.) cuya introducción se pretende en la democracia representativa con el objetivo de complementarla y mejorarla (nunca substituirla), mediante la ampliación de la participación popular en el gobierno de la comunidad y el mayor control de los representantes y gobernantes por parte de los ciudadanos. La finalidad última de la democracia participativa es profundizar en la democracia» ${ }^{23}$.

Es decir, la democracia participativa sería aquel conjunto de instrumentos jurídicos con cuya incorporación y práctica en la democracia representativa se busca lograr una profundización y mejora ${ }^{24}$ en el gobierno de las sociedades

concretas y de las acciones que derivaron del mismo, posiblemente en algo sea homogéneo el 15M: en palabras de Presno Linera, «este entramado ha venido compartiendo el rechazo de una serie de disposiciones normativas y/o de aplicación práctica de las mismas que, en el ámbito político y constitucional, cuestiona que tengamos una democracia real en el sentido reclamado por Habermas: "una democracia en la que los procesos de formación de la voluntad política institucionalizada jurídicamente estén conectados con, y permanezcan porosos a, la formación de una opinión pública no formalmente articulada, lo más argumentativa posible...” » PRESNO LINERA, M. A. (2012): «El 15M y la democracia real», El Cronista del Estado Social y Democrático de Derecho, n. ${ }^{\circ} 25$, p. 38.

${ }^{23}$ RAMÍREZ NÁRDIZ, A., (2012): Guía práctica de la democracia participativa. Conocer la democracia participativa y aprender a usarla, Madrid, Dykinson, p. 109. Todos los elementos, así como la propia definición, que de la democracia directa se ofrecen en las siguientes líneas pretenden ser una propuesta teórica general predicable tanto para España como para terceros países.

24 «Quedan por último, y ésta es la posición en que nos situamos, quienes, —desde luego GIOVANNI SARTORI; según creemos, RUBIO LLORENTE, GARRORENA MORALES, PEDRO DE VEGA...- eluden el ensueño del paradigma ideal, asumen la lógica de la democracia representativa y reflexionan al servicio de una crítica razonable de las enormes carencias de la 
democráticas actuales; mejora que se buscará merced a la consecución, a raíz del ejercicio de dichos instrumentos, de dos objetivos primordiales: la ampliación de la participación directa de los ciudadanos en el gobierno de su comunidad y el aumento del control que dichos ciudadanos ejercen sobre sus representantes políticos y sus gobernantes. Control entendido como rendición de cuentas, como responsabilidad del representante o del gobernante, no como sujeción a mandato imperativo, pues la democracia participativa, tal como aquí se interpreta a la misma, no pretende reinstaurar el mandato imperativo, sino sólo permitir a los ciudadanos fiscalizar más y mejor la labor de sus políticos. De los dos objetivos citados se puede extraer que el concepto de democracia participativa que se defiende en estas páginas gira alrededor de la figura del ciudadano, del individuo, y no de asociaciones, corporaciones o entidades que ejerzan de elementos intermedios o interpuestos entre el ciudadano y las instituciones representativas. Tampoco se sostiene aquí un concepto de democracia participativa que, mediante la interposición entre el ciudadano y su soberanía de una serie de entes corporativos diferentes cuyo objeto sea satisfacer determinados intereses particulares, quiebre el concepto de voluntad popular. La democracia participativa tiene como fin fortalecer el vínculo del ciudadano con su gobierno y con la vida pública, convertirle en un actor político activo e implicado, permitirle valorar más la democracia y transformarle en un sujeto político responsable y formado cívicamente. No se habla aquí de un modelo participativo en el que la relación se establezca entre las instituciones representativas y una pléyade de organizaciones o sujetos colectivos que se autoconstituyan y autodenominen sociedad civil y se arroguen el derecho de relacionarse con dichas instituciones representativas en nombre de una sociedad que no dicen ya representar, sino que afirman constituir. Es alrededor del ciudadano, entendido individualmente, donde se construye la democracia participativa tal como se expone en estas páginas, siendo los instrumentos participativos herramientas jurídicas previstas para la participación de ciudadanos individuales. Una concepción de la democracia participativa construida sobre organizaciones civiles que defienden intereses particulares, no pocas veces sectoriales o corporativos, plantea serias dudas acerca de si serán los intereses generales los verdaderamente promovidos, así como sobre los resultados de la estrecha relación que necesariamente se desa-

teoría clásica de la representación pero, al tiempo, no al servicio de su destrucción, sino de su perfeccionamiento.»Es decir, la democracia participativa, más allá de ensueños o paradigmas ideales no puede más que, asumiendo la democracia representativa, tratar de mejorarla. FERNÁNDEZ-MIRANDA CAMPOAMOR, C. y FERNÁNDEZ-MIRANDA CAMPOAMOR, A., (2003): op. cit., p. 31. 
rrollará entre dichas organizaciones civiles y las instituciones representativas y que podría acabar derivando en un sistema clientelar basado en la adquisición de apoyos de la llamada sociedad civil a cambio de subvenciones a las organizaciones que dicen constituirla. ${ }^{25}$

La democracia participativa se plantea como un complemento ${ }^{26}$ a la democracia representativa que no busca su substitución, sino su mejora ${ }^{27}$ merced a la ampliación ${ }^{28}$ de los niveles de participación directa de los ciudadanos en su gobierno y en el control de sus gobernantes ${ }^{29}$. Pero la propia participación de los

${ }^{25}$ Es importante recordar las palabras de Bobbio cuando indica que «jamás será exagerado sostener contra toda tentación organicista recurrente (no extraña al pensamiento político de izquierda) que la doctrina democrática reposa en una concepción individualista de la sociedad, por lo demás semejante al liberalismo (...)»BOBBIO, N. (1986): El futuro de la democracia, México D. F., Fondo de Cultura Económica, p. 10.

26 «En rigor, cuando se trata de verdaderos procesos democráticos, la democracia participativa no sólo no desplaza a la representativa, sino que la complementa, situándose en un plano diferente que permite minimizar los riesgos de alejamiento entre representantes y representados, a la búsqueda de una mejor calidad de la representación.» FERNÁNDEZ-MIRANDA CAMPOAMOR, C. y FERNÁNDEZ-MIRANDA CAMPOAMOR, A. (2003): op. cit., pp. 28-29.

${ }^{27}$ Es muy interesante de cara a entender el rol complementario y de mejora que pretende suponer la democracia participativa respecto de la democracia representativa, el término «democracia representativa enriquecida» del que se sirve ACOSTA SÁNCHEZ y que indica que se da «si la democracia parlamentaria pura o la constitucional son complementadas con el referéndum legislativo-facultativo, la iniciativa legislativa popular, el referéndum legislativo obligatorio para aprobar determinadas leyes de especial trascendencia, o el referéndum obligatorio para ratificar decisiones políticas sobre determinadas materias.» ACOSTA SÁNCHEZ, J. (1994): op. cit., p. 138.

28 Ampliación de la participación, pero nunca sometimiento del ciudadano a una participación política constante (democracia directa), pues, como bien indica FERNÁNDEZ-MIRANDA CAMPOAMOR, la «libertad de los modernos» por la que optaba CONSTANT y que, en sentido común, parece la única deseable en el presente, no sólo requiere del respeto a los derechos individuales, sino también del respeto de un área privada del ciudadano de la que el Estado permita a cada individuo ocuparse libremente y con el tiempo suficiente, cosa que no sería posible si tuviera que dedicar la mayoría de su tiempo a la participación política. FERNÁNDEZ-MIRANDA CAMPOAMOR, C. y FERNÁNDEZ-MIRANDA CAMPOAMOR, A. (2003): op. cit., p. 26.

29 Como indica Rubio Núñez citando a Manin y a SARTORI «el sistema se articula en torno a mecanismos complementarios a la representación política (...) Su disfuncionalidad comienza cuando dejan de ser instrumentos correctores de hipotéticos defectos en el funcionamiento de la democracia representativa, para convertirse en medios, a cuyo través, al sistema de legitimidad del estado constitucional, se opone un sistema de legitimidad diferente, alternativo. El foco de la legitimidad se desplazaría, como señala BERNARD MANIN "de la voluntad predeterminada de los individuos, al proceso de su formación, es decir, la deliberación misma”. En esta línea avanzan las reivindicaciones de algunos movimientos sociales, como el popularmente conocido como movimiento antiglobalización, que plantean como objetivo "establecer el control de la sociedad sobre sus instituciones tras el fallo de los controles democráticos tradicionales". Ese es el gran peligro de la democracia participativa, la sustitución de la representación por otros criterios de 
ciudadanos no debe quedar ajena a controles externos, del mismo modo que no queda ajena a control la acción política de los representantes elegidos por dicha ciudadanía. Ya sea realizada directamente o por medio de representantes, en democracia toda acción política debe poder ser controlada. Lo contrario supondría un ejercicio del poder de difícil encuadre en el marco democrático. Se podría indicar acertadamente que, en el ejercicio de un instrumento participativo, quién controlará a la ciudadanía y en virtud de qué título, pues, si la ciudadanía sî puede controlar a sus representantes puesto que es ella quien los elige y a quien representan, ¿elige alguien a la ciudadanía a quien ésta tenga que rendir cuentas? Evidentemente no. Sin embargo, en el momento en que un grupo de ciudadanos toma una decisión en el marco de un proceso participativo, dicha decisión trasciende a dichos ciudadanos y se convierte en representativa de la comunidad a la cual representan. Es decir, los asistentes a una asamblea popular de unos presupuestos participativos locales toman decisiones que representan a todo el municipio y los votantes en un referéndum deciden en nombre de todo el país. El elemento representativo es inherente a las decisiones políticas aunque éstas no sean tomadas por representantes, sino por la ciudadanía misma. ${ }^{30} \mathrm{Y}$ donde hay representación debe haber control. Luego los ciudadanos que toman parte en un instrumento participativo sí pueden y deben ser controlados. ¿Por quién? Quepa citar como opción la adoptada por algunos instrumentos participativos con voluntad de pervivencia en el tiempo (especialmente los de ámbito local) que

decisión que como señala Sartori se convierten en "alternativa más que en complemento de la representación (cuando no enmascaran la bien distinta realidad de una manipulación orquestada e impuesta desde lo alto)”.» RUBIO NÚÑEZ, R (2007): «La guerra de las democracias», Asamblea: revista parlamentaria de la Asamblea de Madrid, n. ${ }^{\circ} 16$, p. 87.

${ }^{30}$ El elemento representativo estará siempre y en cualquier caso presente. Así, por ejemplo, en el caso del referendo señala Luciani que «aunque la decisión se atribuye al pueblo mismo y a su "directa" manifestación de voluntad, la mediación, en realidad, siempre está presente, sea porque la opinión pública se forma y se articula sólo gracias a la acción de los partidos, de los grupos, o al menos (sobre todo cuando los grupos y partidos son débiles) de los medios de información; sea porque la agenda política puede estar determinada sólo en mínima parte desde abajo; sea porque la pregunta sometida al pueblo es siempre decidida por los otros; o bien sea porque la interpretación de la voluntad popular, una vez ésta se ha manifestado, confía a pesar de todo en sujetos institucionales o sociales que saben perfectamente cuándo y cómo manipularla y —inclusocuándo y cómo llevarla a cabo.» LUCIANI, M. (2008): «El referéndum. Cuestiones teóricas y de la experiencia italiana», Revista Catalana de Dret Públic, n. ${ }^{\circ} 37$, p. 159. Especialmente relevantes resultan aquí las palabras de Fernández-Miranda Campoamor cuando refiriéndose a la democracia representativa y a la democracia directa indica que «en rigor, en ambos casos, la intermediación es inevitable. En un caso quien intermedia son mayorías circunstanciales que imponen al pueblo su criterio y, en el otro, son representantes elegidos por ese pueblo». FERNÁNDEZ-MIRANDA CAMPOAMOR, C. y FERNÁNDEZ-MIRANDA CAMPOAMOR, A. (2003): op. cit., p. 23. 
disponen de algún tipo de oficina, agencia, o concejalía municipal que vela por el cumplimiento de un año a otro de lo decidido el año anterior, así como por el control y la eficiencia del procedimiento en su conjunto. Igualmente, en todos los instrumentos participativos mínimamente organizados acostumbra a darse una relación de cooperación y control de los órganos representativos electos con los ciudadanos que participan en el instrumento participativo. Es decir, las decisiones no se toman unilateralmente por los ciudadanos, sino que surgen de un proceso conjunto entre ciudadanos y órganos representativos, entre los que existe un control mutuo.

La democracia participativa no es ni revolucionaria ni pretende cambiar el modelo de gobierno representativo existente en el presente ${ }^{31}$, sino que, por el contrario busca afianzarlo y asegurarlo ante potenciales procesos de degeneración ${ }^{32}$. Los instrumentos participativos de la democracia participativa se incorporarán siempre a la democracia representativa a modo de complemento, nunca pretendiendo alterar el núcleo esencialmente representativo del sistema democrático actual ${ }^{33}$ o la función del representante respecto de la Nación, sino sólo con la voluntad de permitir una mayor participación e implicación de los ciudadanos en la cosa pública. En este sentido, la concepción de la democracia participativa que se sostiene en este artículo no concibe al representante, en ningún caso, como un mero delegado de sus

31 «Rechazando la falsa antítesis entre democracia representativa y otras formas de participación sustantiva de los ciudadanos en la vida pública, no podemos olvidar la necesidad de fortalecer el impulso democrático para encontrar nuevas formas de participación de los ciudadanos en las decisiones que les afectan. Y esto sólo es posible hacerlo a través de una configuración jurídica distinta que, respetando los principios del sistema representativos como principios básicos del sistema, dé entrada a formas de realización de la participación política.» RUBIO NÚÑEZ, R. (2007): op. cit., p. 96.

32 Si bien el momento histórico es diferente y las circunstancias dispares, la motivación es muy similar a la que en el primer tercio del siglo xx defendía Kelsen para la introducción en la democracia representativa de instrumentos de, usando la terminología de la época, democracia directa. En palabras de Otto, «aunque KELSEN propugna sistemas de democracia directa, como el referendum, cuyas posibilidades de uso plebiscitario-autoritario no estaban aun tan claras como hoy, sus propuestas se dirigen a una mayor vinculación del Parlamento con el elector, lo que no es posible sin una activación de éste y, por tanto, sin una prolongación de su actividad política más allá de la acción de depositar su voto en una urna.» KELSEN, H. (1977): Esencia y valor de la democracia, Madrid, Guadarrama, Colección Punto Omega.

33 «(...) no existe alternativa a la democracia representativa, que es la única democracia posible, que podrá ser susceptible de mejora, de incremento de la participación, de mayor aproximación a los individuos cuya voluntad es necesariamente el punto de partida democrático de toda fabricación de la voluntad política.» FERNÁNDEZ-MIRANDA CAMPOAMOR, C. y FERNÁNDEZ-MIRANDA CAMPOAMOR, A. (2003): op. cit., p. 30. 
representados, sino como un representante de la Nación. ${ }^{34}$ Por ello, la democracia participativa no es un modelo utópico o adánico que desee eliminar el modelo político representativo creando otro modelo nuevo ${ }^{35}$, sino que se fundamenta en el presupuesto de tomar la democracia representativa como la forma de gobierno más adecuada para las sociedades actuales ${ }^{36}$, pero tratando de dotarla de una mayor profundidad democrática permitiendo a los ciudadanos participar en mayor medida que mediante la simple emisión periódica de su voto para la elección de representantes y gobernantes. No se pone en duda la necesidad de la representación ${ }^{37}$ como

34 Representante que, en palabras de de Vega, tendría asignada «la función de ser expresión y ritualización (Vergegenwärtingung) de esas verdades sociales, de esos valores e intereses en que se plasma la opinión pública. El representante, pues, no traduce la voluntad concreta del representado — como han descrito con acierto Schmitt y Leibholz — sino que expresa la voluntad política ideal de la Nación o del pueblo.» VEGA, P. de, (1998): op. cit., p. 7. Una mayor participación de los ciudadanos no tiene por qué subvertir la condición representativa del representante, sino sólo complementarla, ciertamente tal vez retirando de los representantes determinadas competencias que se trasladen a la ciudadanía, pero nunca modificando el estatuto y características mismas de la representación y de los representantes como tales. Si los ciudadanos deciden directamente en determinados ámbitos no debe considerarse que esto rompe, duplica o modifica el esquema Nación-representación-representantes (en el que la Nación, mediante la representación, cede el ejercicio — que no la titularidad — de su soberanía a los representantes) introduciendo un cuerpo externo constituido por los propios ciudadanos decidiendo directamente, sino tan sólo que en determinadas competencias la Nación no transmitirá el ejercicio de su soberanía a los representantes, sino que lo mantendrá y lo ejercerá directamente mediante los instrumentos participativos.

35 No se trata aquí de la substitución del parlamento por un hipotético gobierno directo de los ciudadanos que llevara a Sartori, con gran ingenio, a indicar «Es decir: si el cirujano es malo, operémonos nosotros mismos; si el profesor es malo, prescindamos de él. Como dijo Mencken, "para todo problema humano puede encontrarse una solución simple, clara y equivocada”.» SARTORI, G. (1999): «En defensa de la representación política», Claves de razón práctica, n. ${ }^{\circ}$ 91, p. 2.

36 «En ese sentido, cabría decir que la democracia constitucional exige, por principio, la democracia representativa. Y así fue, en el Estado constitucional, hasta el presente, sin que hoy, pese a las modernas facilidades telemáticas (voto electrónico, etc.), hayan decaído aquellas razones (que son teóricas y no sólo prácticas). Lo que no impide, claro está, que como complemento de la democracia representativa, y no como su sustitución, quepa admitir determinados instrumentos de democracia directa (referéndums, especialmente) para la adopción de decisiones de muy especial trascendencia, o determinadas fórmulas de participación, que no de decisión, directa (por ejemplo, la iniciativa legislativa popular) en el Estado constitucional. Así se ha hecho en numerosos Estados constitucionales sin que por ello quiebre la democracia representativa, siempre que aquellos instrumentos o fórmulas se presenten como excepción y no como regla general, de suerte que no sirvan para deslegitimar a la representación política, que ha de considerarse, por lo antes dicho, como el sustento de la democracia constitucional.» ARAGÓN REYES, M. (2008): «Democracia y Parlamento», Revista Catalana de Dret Públic, n. ${ }^{\circ} 37$, Generalitat de Catalunya, Escola d’administració pública de Catalunya, pp. 130-131.

37 Al menos desde estas líneas no se pretende caer en posturas como la que señalaba Sartori al indicar que « $(\ldots)$ hay una tendencia creciente de opinión (tanto de masas como entre los inte- 
mecanismo nuclear para articular el gobierno, pero sí se pretende complementar el modelo representativo con fórmulas de participación directa. No se pretende, ni mucho menos, desde estas páginas poner en duda la prohibición del mandato imperativo como elemento característico de la democracia representativa. La introducción de mecanismos participativos no debe cambiar la condición del representante, ni su relación con sus electores, hasta el punto de convertirle en un delegado de los mismos, sino sólo permitir a aquellos fiscalizar mejor a éste. ${ }^{38}$

Si bien la democracia participativa puede darse en cualquier ámbito territorial, aquel que más la caracteriza es el ámbito de lo local, del municipio. En una paradójica vuelta al origen de la democracia directa ateniense, que se circunscribía a la ciudad y a grupos de personas no mayores de unos pocos miles de individuos, en el presente se observa un desarrollo muy contenido de la democracia participativa tanto a nivel nacional ${ }^{39}$, como regional ${ }^{40}$, mientras que es en el

lectuales) que postula lo que llamo (en italiano) "direttismo", es decir, directismo, con la consiguiente relegación de la representación a un papel menor o, incluso, secundario. Ante ello, mi postura es que la representación es necesaria (no podemos prescindir de ella) y que las críticas de los directistas son en gran parte fruto de una combinación de ignorancia y primitivismo democrático.» Sartori, G. (1999): op. cit., p. 2.

${ }^{38}$ Hay que afirmar con Sartori que «la respuesta a la cuestión de si la prohibición del mandato es una condición necesaria y ciertamente inherente a la democracia representativa es definitivamente afirmativa. Por mucho que los votantes deseen disponer de representantes que operen como su chico de los recados, como los ejecutores de sus instrucciones, es necesario resistirse a esta exigencia y decirles que unos mandatarios al servicio estricto de sus concretos electores no harían sino menoscabar la democracia representativa.»SARTORI, G. (1999): op. cit., p. 4.

39 El ejemplo perfecto es España, donde desde 1978 sólo ha habido dos referendos consultivos nacionales (OTAN en 1982 y Constitución Europea en 2005) y sólo una iniciativa legislativa popular desembocó en una ley al ser subsumida en otra iniciativa y culminar en la proposición de ley sobre reclamación de deudas comunitarias de 1996. El otro instrumento participativo nacional (el referendo ratificatorio de la reforma constitucional) nunca se ha utilizado. RAMÍREZ NÁRDIZ, A. (2012): op. cit., pp. 56-72.

40 Siguiendo con el ejemplo español, el desarrollo regional o autonómico de la democracia participativa es más amplio que el nacional, pero su práctica es también limitada. Se han realizado referendos ratificatorios de cuatro de los diecisiete estatutos de autonomía (Cataluña, País Vasco, Galicia y Andalucía). Ninguno de los restantes estatutos prevé esa posibilidad, tampoco los recientemente reformados. Las CCAA apenas dedican atención a los instrumentos participativos en sus estatutos, si bien los estatutos reformados sí acostumbran a regular el amplio espectro de las consultas populares en un artículo específico (art. 122 del Estatuto de Cataluña, art. 71.27. ${ }^{\text {a }}$ del Estatuto de Aragón o art. 78 del Estatuto de Andalucía). Se han redactado leyes autonómicas sobre la iniciativa legislativa popular (Ley 7/1984 de Aragón, Ley 8/1986 del País Vasco; Ley 5/1993 de la Comunidad Valenciana o Ley 1/2006 de Cataluña), sobre consultas populares locales (Ley 2/2001 de Andalucía o Ley Foral 27/2002 de Navarra), sobre consultas populares por vía de referendo (Ley 4/2010 de Cataluña), o sobre todo el ámbito participativo en su conjunto (Ley 11/2008, de 3 de julio, de Participación Ciudadana de la Comunidad Valenciana), pero lo cierto 
ámbito local donde más se practican los instrumentos participativos y donde más se innova a la hora de crear otros nuevos ${ }^{41}$. Este sería el panorama normativo general en Europa, si bien hay que destacar que las más recientes constituciones iberoamericanas (Venezuela, Ecuador, Bolivia, etc.) recogen múltiples instrumentos participativos novedosos, desconocidos en la práctica europea y cuya aplicación, así como la filosofía que late detrás de ellos, resulta no poco polémica en muchos $\operatorname{casos}^{42}$.

es que la práctica de la democracia participativa no es habitual y su uso resulta más esporádico que continuado. Con el agravante de que en ocasiones se utilizan los instrumentos participativos para tratar de subvertir el ordenamiento: caso de la Ley del Parlamento Vasco 9/2008, de 27 de junio, que fue declarada inconstitucional por la STC 103/2008, de 11 de septiembre, por convocar un referendo —al que llamaba consulta popular- sin tener competencia para ello. RAMÍREZ NÁRDIZ, A. (2012): op. cit., pp. 73-84.

${ }^{41}$ La explicación para el abundante desarrollo de experiencias y regulaciones locales de democracia participativa gira, más que probablemente, alrededor de la buena relación riesgo-beneficio que de su puesta en práctica pueden extraer las corporaciones locales. Un gobierno municipal que ponga en marcha un instrumento participativo obtendrá de partida un rédito positivo de carácter publicitario (en principio, cualquier actividad que suponga una mayor participación de los ciudadanos siempre es vista positivamente por los mismos) y, si es capaz de orientar acertadamente a los vecinos del municipio, conseguirá fácilmente que lo decidido por los mismos en la consulta popular, en los presupuestos participativos, etc. sea justo aquello que el ayuntamiento deseaba de inicio. Si los beneficios son elevados, los riesgos son escasos, pues habitualmente (caso de España) la participación de los ciudadanos no llega hasta el punto de ser ellos los que toman la decisión final, la cual acostumbra a quedar en manos de la corporación municipal, con lo que, en caso de que los vecinos decidieran algo contrario a la voluntad del gobierno municipal, siempre existiría la posibilidad de demorarlo, evitar su cumplimiento o, en casos extremos, no cumplirlo. Derivado de esto, en España, por ejemplo, los reglamentos de participación ciudadana, las concejalías del ramo y las experiencias participativas son múltiples y mucho más numerosas que las experiencias dadas en otros ámbitos territoriales. Evidentemente, en no pocos casos detrás de esta situación, tan positiva en principio, se esconde un ánimo populista y de publicidad por parte del gobierno municipal, cuando no, sencillamente, una forma «elegante» de clientelismo con las asociaciones ciudadanas del municipio. Para comprobar si existe o no una verdadera voluntad participativa por parte del ayuntamiento es recomendable observar una serie de elementos: la cuantía de la partida presupuestaria que se dedica a actividades participativas en proporción a los habitantes del municipio; si la estructuración de la participación gira alrededor de los ciudadanos entendidos individualmente o, por el contrario, si gira alrededor de asociaciones de ciudadanos (mucho más fácilmente controlables — mediante subvenciones — desde el poder municipal); y, especialmente, la intensidad que tiene la participación de los ciudadanos en los instrumentos participativos puestos en marcha, la cual podrá ir desde el mero intercambio de información entre ellos y el ayuntamiento, hasta la toma real de decisiones respetadas por el gobierno municipal. La forma y modo en que cada municipio maneje estos tres elementos será definitoria de si la voluntad del ayuntamiento es realmente participativa o meramente populista y publicitaria.

42 Sin duda, el gran peligro de la democracia participativa consiste en perder su esencia de profundización democrática en manos de líderes políticos cuyo verdadero objetivo sea servirse de 


\section{La democracia participativa es un concepto reciente ${ }^{43}$ que surge en gran} medida a causa ${ }^{44}$ y como respuesta a la crisis de la representación ${ }^{45}$, cuyo término denominador es aun más reciente. Como tal, es de creación doctrinal, pues tanto en la legislación como en la jurisprudencia, aun en la más actual ${ }^{46}$, se usan

ella como herramienta populista o plebiscitaria que les permita legitimar su gobierno dirigiéndose directamente a la ciudadanía y evitando así los controles y frenos propios del parlamentarismo y de la democracia representativa. En Iberoamérica la sospecha se materializa en gobiernos de tendencias populistas sobre los que recae la recurrente acusación de que utilizan los instrumentos de la democracia participativa a modo de vía para evitar al parlamento (donde reside su oposición) y acudir directamente a la ciudadanía cayendo en prácticas típicamente demagógicas, plebiscitarias e, incluso, caudillistas. LISSIDINI, A. (2008): La democracia directa en Venezuela: ¿democracia participativa o democracia plebiscitaria?, Zurich, C2D, p. 13. Para Kornblith el uso de la Democracia Participativa en Venezuela «ha sido intenso; ha carecido del debido desarrollo legal e institucional, lo que se ha traducido en disposiciones acomodaticias condicionadas por las circunstancias; la activación de la DD enfrentó más obstáculos bajo la Constitución de 1999 que en el marco de la Constitución de 1961; y cuando los instrumentos de la DD fueron enarbolados por sectores opositores al gobierno tropezaron con severos impedimentos para su activación.» KORNBLITH, M. (2007): Democracia Directa y Revocatoria de Mandato en Venezuela, Buenos Aires, International IDEA, p. 3.

43 Puede fijarse su aparición a finales de los años sesenta y primeros setenta del siglo xx, tanto en Europa como en los EEUU, como parte del cambio generalizado de paradigma social que las sociedades occidentales vivieron en aquellos años. RAMÍREZ NÁRDIZ, A. (2012): op. cit., pp. 15-16.

44 «Como no es de extrañar tampoco que frente a la democracia representativa se enarbolen los argumentos de la democracia de la identidad rousseauniana, bien apelando a los mecanismos clásicos de la democracia directa (referéndum, iniciativa popular, etcétera), bien bajo las novedosas fórmulas de la llamada democracia participativa (Zampetti) o la democracia plebiscitaria (Mercadante).» VEGA, P. de, (1993): op. cit., p. 203.

45 «Lentamente se ha comenzado a cuestionar abiertamente el concepto de representación como pilar fundamental del principio democrático; cuestionando si los sistemas representativos son democráticos, y si lo son suficientemente. El sistema representativo se presenta insuficiente. Como señala Sartori, su problema es la debilidad de la elección, convertida en el único elemento legitimador. La sociedad reclama una mayor relación con sus gobernantes y la doctrina se ha fijado, en los últimos años, en el concepto de participación política. Se buscan formas alternativas, o complementarias, a la representación.» $\mathrm{O}$, citando a DE VEGA — aunque resulte evidente que su visión de la democracia participativa, tal y como él la entiende, no sea positiva-, la democracia participativa es «el resultado inconsecuente y procaz de dos grandes frustraciones históricas, la pérdida de legitimidad de la democracia representativa y la incapacidad del mercado para crear por sí solo unos niveles mínimos de integración social.» RUBIO NÚÑEZ, R. (2007): op. cit., pp. 81 y 88; VEGA, P. de, (1998): op. cit., p. 30.

${ }^{46}$ Ejemplo de esto es la STC 103/2008, de 11 de septiembre, que en su fundamento jurídico $2 .^{\circ}$ utiliza los términos democracia directa y fenómeno participativo, pero ignora el de democracia participativa. Con anterioridad a esta sentencia, la STC 119/1995, de 17 de julio, ya utilizó en sus fundamentos jurídicos $3 .^{\circ}$ y $4 .^{\circ}$ las expresiones democracia directa y fenómeno participativo con el mismo significado que el que les otorga la STC 103/2008. 
todavía en la mayoría de los casos términos tales como democracia directa, semidirecta, etc. para referirse a lo que la doctrina mayoritaria considera como democracia participativa; además, en el ámbito de la participación se utilizan otros términos que acostumbran a confundirse con los anteriores, tales como participación ciudadana, gobernanza, fenómeno participativo, etc. ¿Cuál es la diferencia entre todos estos términos ${ }^{47}$ La confusión más habitual suele ser entre democracia participativa y democracia directa. La diferencia fundamental entre ambas consiste en que, si bien la primera busca ser un complemento a la democracia representativa, la segunda llama (tanto por su origen remoto ateniense, como por su contenido y el propio término que la nombra: directa) a la substitución de la democracia representativa por una fórmula de gobierno popular, directo y permanente, en el cual la ciudadanía actúe de forma sostenida en el tiempo como poder constituyente ${ }^{48}$, rigiéndose en la toma de sus decisiones por la estricta regla de la mayoría ${ }^{49}$. Por su parte, la democracia semi-directa es, en términos generales, el término que a lo largo de gran parte del siglo xx hizo referencia a lo que en el presente se entiende por democracia participativa, con

${ }^{47}$ La diferenciación terminológica hecha a continuación se basa en el glosario contenido en la obra anteriormente citada: RAMÍREZ NÁRDIZ, A. (2012).

${ }^{48}$ Es necesario traer en este punto el famoso argumento de Constant advirtiendo de los riesgos de la «libertad de los antiguos» y optando clara y decididamente por la «libertad de los modernos», pues esta última «es el derecho de cada uno a no estar sometido más que a las leyes, a no poder ser ni arrestado, ni detenido, ni muerto, ni maltratado de manera alguna a causa de la voluntad arbitraria de uno o de varios individuos (...) comparen ahora esta libertad con la de los Antiguos. Aquella consistía en ejercer de forma colectiva pero directa, distintos aspectos del conjunto de la soberanía, en deliberar en la plaza pública (...) pero a la vez que los Antiguos llamaban libertad a todo esto, admitían como compatible con esta libertad colectiva la completa sumisión del individuo a la autoridad del conjunto. No se encuentra en ellos casi ninguno de los beneficios que, como constitutivos de la libertad de los Modernos, acabamos de ver». CONSTANT, B. (1989): «De la libertad de los Antiguos comparada con la de los Modernos», Escritos políticos, Madrid, Centro de Estudios Constitucionales, pp. 259-260.

49 Es de rigor unirse aquí a lo apuntado por Fernández-Miranda Campoamor cuando, habiendo diferenciado previamente entre democracia directa y democracia participativa, indica sobre el rol de la mayoría en la democracia directa que «la única forma de defender la democracia directa es considerando la regla de la mayoría, no como un mecanismo de reducción de la complejidad para lograr una decisión, sino como el principio legitimador y justificador del poder político. Así la validez del Derecho descansaría en el criterio exclusivo de que lo han ordenado los más y la democracia exigiría que la voluntad de los más prevaleciese sobre la voluntad de los menos. Evidentemente, no creemos que ese sea el fundamento de la democracia ni su principio legitimador (...) es la libertad de todos lo que legitima la democracia, con el principio de las minorías, comenzando por el individuo como máxima minoría, y no la regla de la mayoría como fundamento del sistema.» FERNÁNDEZ-MIRANDA CAMPOAMOR, C. y FERNÁNDEZ-MIRANDA CAMPOAMOR, A. (2003): op. cit., pp. 27-28. 
la salvedad de que la democracia participativa incorpora elementos (como la importancia de lo local o algunos de los instrumentos participativos) que no se contemplaban en la democracia semi-directa. Por su parte, la participación ciudadana es un concepto más general que el de democracia participativa, que la incorpora (todo lo que es democracia participativa es participación ciudadana) pero que incluye también otras actividades de participación política directa que, por su menor intensidad participativa, no pueden tenerse por propias de la democracia participativa (no todo lo que es participación ciudadana es democracia participativa). Otro término de uso frecuente es fenómeno participativo, el cual ha sido utilizado por el Tribunal Constitucional (STC 103/2008, de 11 de septiembre y STC 119/1995, de 17 de julio) y con el que se refiere a todas las formas de participación, tanto políticas como no políticas, que la Constitución prevé que pueden ejercitar los ciudadanos (se incluiría aquí la democracia participativa, pero también otras manifestaciones de otros derechos ajenos al de participación política — recogido en nuestra Constitución en el art. 23.1 CE—). En este mismo ámbito conceptual, con gobernanza se alude a una visión en red del gobierno, en el que los distintos actores sociales, tanto públicos como privados, tanto individuales como colectivos, actúan conjuntamente para la toma de decisiones que afectan al conjunto de la comunidad. Son todos, en definitiva, conceptos que se interrelacionan, que ocupan espacios en muchos casos parcialmente superpuestos, que son mayoritariamente novedosos y que, por ello, son fácil elemento para la confusión. La diferenciación entre unos y otros no es un mero pasatiempo doctrinal, sino que, por el contrario, resulta especialmente relevante como indicio de cara a comprobar si el instrumento participativo concreto al que nos refiramos forma parte de un intento sincero de profundizar y mejorar la democracia o es, simplemente, una herramienta en manos de una administración pública populista. ${ }^{50}$

La democracia participativa no tiene una ideología determinada. No es necesariamente de derechas o de izquierdas, progresista o conservadora. Desde luego, siempre es democrática (a salvo de los populismos que se sirvan de ella pervirtiéndola y utilizándola para fines distintos de los que le son propios), pero la experiencia demuestra que puede ser puesta en marcha por gobiernos de un signo u otro. Como tal, la democracia participativa no es más que un conjunto de instrumentos jurídicos alentados por el fin común de intentar profundizar en

${ }^{50}$ No será la mismo que un gobierno municipal lleve a cabo instrumentos de democracia participativa (la cual implica una participación activa de los ciudadanos en algún momento de proceso participativo) a que practique exclusivamente actuaciones propias de la participación ciudadana (ámbito este último mucho más amplio en el número de actividades posible, pero siempre y en cualquier caso con una intervención activa del ciudadano mucho menor). 
la democracia acercando a los ciudadanos a su gobierno, por ello pueden ser igualmente materializados por administraciones de distinto signo ideológico siempre que compartan la misma idea de partida, cual es la mejora de la democracia mediante el aumento de la participación. ${ }^{51}$ Estos instrumentos de la democracia participativa son múltiples y su número se encuentra (particularmente en el ámbito local) en constante proceso de ampliación. Se podrían organizar en dos categorías fundamentales según su ámbito territorial de aplicación. Así, se hablará de instrumentos participativos generales, los cuales se pueden practicar y se practican en cualquier ámbito territorial (referendos, consultas populares, iniciativas populares, revocatorias de mandato, etc.), y de instrumentos participativos eminentemente locales, los cuales tienen su ámbito natural - puede extenderse a otros, pero no es lo habitual — en la esfera de lo local (presupuestos participativos, jurados ciudadanos, asambleas populares, etc.).

\section{La democracia participativa como respuesta a la crisis de la representación}

Si la crisis de la representación tiene entre sus efectos la desconexión entre gobernantes y gobernados, la ruptura del vínculo representativo entre representados y representantes y el distanciamiento del ciudadano de la vida pública y de la democracia representativa como modelo de gobierno, el rol que puede jugar la democracia participativa consiste, precisamente, en contribuir a revertir o, cuando menos, contribuir a paliar, el fenómeno citado acercando e implicando de nuevo al ciudadano en la vida pública mediante un aumento de su participación en el

51 Así, frente a experiencias marcadamente izquierdistas (de hecho, autodenominadas socialistas o, incluso, revolucionarias) de introducción de instrumentos participativos, como la llevada a cabo en Venezuela desde la aprobación de la Constitución de 1999, aparecen otras de signo ideológico muy dispar como las promovidas en los EEUU durante la presidencia de Jimmy Carter (1977-1981) y que trataban de frenar lo que consideraban un excesivo intervencionismo del Gobierno Federal en el ámbito local. No obstante, la materialización más cercana de lo dicho se encuentra en la experiencia municipal española en la que, por ejemplo, dentro de una misma comarca como L'Alacantí en la provincia de Alicante convivieron durante varios años dos convocatorias de presupuestos participativos en dos municipios limítrofes como eran Alicante y San Juan de Alicante que, sin embargo, estaban gobernados por dos partidos políticos distintos como eran respectivamente el PP y el PSOE. RAMÍREZ NÁRDIZ, A. (2012): op. cit. (para el estudio del caso venezolano, capítulo 3.5); FINKIELKRAUT, A. (1982): La nueva derecha norteamericana. La revancha y la utopía, Barcelona, Anagrama (para el estudio del caso de los EEUU); RAMÍREZ NÁRDIZ, A. (2009a): «Los presupuestos participativos como instrumento de democracia participativa. La experiencia de San Juan de Alicante», Cuadernos Constitucionales de la Cátedra Fadrique Furió Ceriol, n. ${ }^{\circ}$ 66, Universidad de Valencia, pp. 127-144 (para el análisis de los presupuestos participativos de San Juan de Alicante). 
gobierno y en el control del gobierno de su comunidad. La crisis de la representación viene dada por una serie de circunstancias que difícilmente podría la democracia participativa por sí sola corregir por completo. La democracia participativa per se no puede modificar las actuaciones y la dinámica de los partidos políticos en las democracias actuales, ni puede cambiar la ley electoral, ni puede reformar la Constitución, ni, mucho menos, puede transformar la mentalidad y la actitud de los ciudadanos hacia su gobierno y hacia su intervención en el mismo, pero sí puede ser un instrumento, un conjunto de instrumentos, que colaboren con dichos cambios. En concreto, el ejercicio de la democracia participativa, a través de sus diferentes instrumentos, puede producir los siguientes efectos:

a) mejora del intercambio de información entre las administraciones públicas y los ciudadanos: el primer elemento que pone en marcha cualquier instrumento participativo es el intercambio de información entre administradores y administrados. Este intercambio aumenta la transparencia pública y hace que el ciudadano mejore su nivel de confianza en sus gobernantes ${ }^{52}$.

b) aumento de la participación de los ciudadanos ${ }^{53}$ : la participación en los instrumentos participativos colabora en el aumento de la participación política del ciudadano, al concienciarse de la relevancia e importancia de su participación en los asuntos públicos ${ }^{54}$.

52 Nunca hay que olvidar que la democracia es, por definición, un modelo de gobierno cuyas acciones deben ser lo más públicas, transparentes y accesibles al conocimiento público que sea posible. El gobierno absoluto en el que los súbditos no tienen más rol que el del sometimiento al gobernante es el gobierno de los arcana imperii, el gobierno que se realiza en secreto, sin consultar ni informar a los súbditos, sin embargo, la democracia, la cual surge de los ciudadanos y gobierna en nombre de los ciudadanos, requiere de la publicidad, del debate público y de la mayor transmisión de información entre gobernantes y gobernados que, dentro de los límites impuestos por la seguridad y los derechos de los propios ciudadanos, sea posible. En gran medida, la transparencia, la publicidad y la calidad y normalidad en la transmisión de la información en la acción de gobierno y entre gobernantes y gobernados es síntoma de la calidad democrática de una sociedad.

53 No se pretende con la democracia participativa obligar o exigir al ciudadano que participe en la vida pública, sino sólo darle la oportunidad de que lo haga y que lo haga más si así lo desea. No se está aquí, pues, en posturas extremas como la de la famosa frase de Pericles, citado por Tucídides en La guerra del Peloponeso, que considera seres inútiles a los ciudadanos que no participan en la vida pública, o como la de ROUSSEAU en El Contrato Social que tiene por perdido el Estado en el mismo momento en que los ciudadanos dicen «iqué me importa!» para indicar su carencia de interés por la cosa pública.

54 Y como indica Bobbio, citando a Stuart Mill en «Sobre la mejor forma de gobierno» de la obra Consideraciones sobre la democracia representativa, los ciudadanos se distinguen en activos y pasivos siendo que, en general, «los gobernantes prefieren a los segundos porque es más fácil tener controlados a súbditos dóciles e indiferentes, pero la democracia necesita de los primeros.» BOBBIO, N. (1986): op. cit., pp. 24-25. 
c) aumento de la formación cívica de los ciudadanos: todos los instrumentos participativos implican, en mayor o menor medida, dependiendo de cuál se trate, la necesidad por parte del ciudadano de ampliar sus conocimientos sobre la democracia y el Derecho, así como sobre la materia tratada en dicho instrumento participativo ${ }^{55}$. Esta mejora de conocimientos ayuda para la formación de una sociedad más preparada democráticamente que conozca mejor la gestión pública, sus costes, sus necesidades, sus fuerzas, sus debilidades, etc. y con ello se contribuye a que el ciudadano esté en disposición de tomar decisiones políticas más argumentadas, más maduras y, posiblemente, más acertadas ${ }^{56}$.

d) identificación más intensa del ciudadano con la comunidad de la que forma parte: la falta de participación favorece el aislamiento social; la participación e implicación del ciudadano en los instrumentos participativos le hace relacionarse más con sus vecinos y conciudadanos, identificarse más con ellos (con sus problemas, sus necesidades, etc.) y mejorar su integración en el todo social. Una sociedad más participativa es una sociedad más unida y, por tanto, más fuerte.

e) revalorización de la democracia como modelo político: el ciudadano que participa en los instrumentos participativos lo hace no sólo desde el respeto pasivo a los principios democráticos, sino desde el ejercicio activo de los mismos (igualdad de voto en unos presupuestos participativos, libertad de expresión y respeto a las opiniones discordantes en una asamblea popular, etc.). Esta práctica personal de los valores democráticos lleva al ciudadano a comprenderlos mejor (no sólo en sus ventajas y beneficios, sino también en sus inconvenientes y deberes), a identificarse con ellos y a tenerlos por propios (es decir, se pasa de valorar, por ejemplo, la igualdad como bien colectivo —ajeno, en gran medida, pues, al

55 Hay que entender la palabra «necesidad» aquí utilizada desde un doble punto de vista: la posibilidad que el ciudadano tiene de ampliar su formación y conocimientos gracias a los instrumentos participativos; pero también el deber desde la responsabilidad que dicho ciudadano tiene de ampliar su formación y conocimientos. Difícilmente un modelo de gobierno basado en que los ciudadanos decidan en un mayor número de ocasiones será factible si éstos no tienen una formación suficiente para decidir razonada y fundadamente. En este sentido, la democracia participativa supone un aumento de posibilidades para el ciudadano, pero también una exigencia de mayores responsabilidades y deberes. En palabras de Sartori «la democracia representativa exige del ciudadano mucho menos que la directa y puede operar aunque su electorado sea mayoritariamente analfabeto (véase la India), incompetente o esté desinformado. Por el contrario, una democracia directa en tales circunstancias está condenada a la autodestrucción. Un sistema en el que los decisores no saben nada de las cuestiones sobre las que van a decidir equivale a colocar la democracia en un campo de minas.» SARTORI, G. (1999): op. cit., p. 6.

${ }^{56}$ En palabras de RUBIO NÚÑ̃Z «En resumen, el gobierno, no del pueblo, ni de las masas, de los ciudadanos, como personas educadas y formadas por la propia deliberación, por sus contribuciones mutuas.» RUBIO NÚÑEZ, R. (2007): op. cit., p. 86. 
ser de todos en general, pasa a no ser de nadie en particular- a tenerlo como bien propio, personal, privado del individuo ${ }^{57}$ ).

f) mayor respaldo popular de las decisiones tomadas por los poderes públicos: al contar con la participación de los ciudadanos y al haber podido ser fiscalizadas por estos, las decisiones políticas gozan de un mayor respaldo popular.

g) mejora de la imagen de los políticos, los partidos políticos y la política en general ${ }^{58}$ : el mayor control sobre los representantes y gobernantes que permiten los instrumentos participativos, así como la mayor fiscalización sobre la labor política que implican, aumenta la transparencia de la acción política, dificulta las prácticas ajenas a la legalidad y mejora la imagen pública de la política.

En un modelo ideal, todos estos efectos redundan en la obtención de un resultado final general cual es la mejora de la calidad democrática de una sociedad. El ciudadano práctica más la democracia gracias a los instrumentos participativos, controla mejor a sus gobernantes y se intensifican sus relaciones con

57 Juega aquí la famosa diferenciación de Schumpeter entre la esfera de responsabilidad directa y la esfera de responsabilidad indirecta. SCHUMPETER, J. A. (1971): Capitalismo, Socialismo y Democracia, Madrid, Aguilar. El razonamiento sostenido desde las presentes páginas indica que al relacionarse más intensamente con su derecho de participación política, gracias a la democracia participativa, este derecho pasará de ser parte de la esfera de responsabilidad indirecta del ciudadano a ser parte de su esfera de responsabilidad directa; es decir, al dedicar el ciudadano más tiempo a este derecho, lo valora en más alta medida y se esfuerza más en mantenerlo y defenderlo. En el fondo (y perdón por la leve transgresión motivada por la voluntad de seguir la línea del análisis de Schumpeter), la democracia es como el amor: hay que practicarla para que no se eche a perder. Siempre se podría argumentar, por supuesto, que el argumento de Schumpeter está siendo aquí invertido, pues él afirmaba que valorar un bien hace dedicarle más tiempo y aquí se indica que, dedicándole más tiempo, se valorará más dicho bien (en este caso, la participación política y, derivada de ésta, la democracia misma); la respuesta inmediata podría ser: bien, el ciudadano medio dedica mucho más tiempo a realizar tareas del hogar que a estar en la playa tomando el sol y no por ello valora más dichas tareas que yacer tumbado en la arena. A esto habría que responder que no es lo mismo un derecho que una obligación y que los derechos sí tienden a ser más valorados a más se conocen y practican (un niño pequeño no valora la educación, es más, no le gusta, pero un adulto ya educado sí la valora y le gusta haber sido educado). Por tanto, el razonamiento recogido en estas páginas no es una inversión del de Schumpeter, sino una ampliación del mismo añadiéndole una fase previa: se valora un bien y por ello se dedica más tiempo a él, pero se valora dicho bien porque previamente se ha dedicado suficiente tiempo como para conocerlo y, derivado de ello, valorarlo.

58 Se utiliza aquí la expresión triple usada por el CIS en sus barómetros de noviembre de 2012 y noviembre de 2013 , estudios n. ${ }^{\circ} 2966$ y n. ${ }^{\circ} 3005$, citados ambos en estas páginas, sobre los mayores problemas de los españoles, donde sitúa a estos tres elementos como tercer (2012) y cuarto (2013) mayor problema de los españoles sólo superado por el desempleo, la crisis económica y (en 2013) la corrupción. CIS (2012): op. cit., cis.es, consultado el 17/01/2013 y CIS (2013): op. cit., cis.es, consultado el 02/02/2014. 
el grupo, la sociedad, de la que forma parte. Ejemplos prácticos en los que se demuestre la utilidad real de los instrumentos participativos hay muchos. Por citar algunos, quepa hacer referencia a tres ejemplos de un mismo instrumento participativo: los presupuestos participativos desarrollados en Porto Alegre (Brasil), en el Estado de Kerala (India) y en la localidad de San Juan de Alicante (España). Los presupuestos participativos son un

«instrumento participativo (en principio local, aunque en teoría también puede ser regional o incluso nacional) mediante el cual el gobierno municipal consigna una parte del presupuesto del municipio (generalmente del presupuesto dedicado a obras y servicios) para su distribución y utilización en aquellos objetivos que decida no el gobierno municipal unilateralmente, sino dicho gobierno municipal en colaboración con los vecinos del municipio. La participación de los vecinos se materializará en distintas acciones a lo largo de las diferentes fases del proceso. Estas acciones irán desde la propuesta de objetivos, hasta la decisión sobre objetivos» ${ }^{59}$.

El modelo brasileño de Porto Alegre supuso el primer gran ejemplo con repercusión internacional de los presupuestos participativos. Tras la llegada del Partido de los Trabajadores al poder municipal se puso en marcha en 1989 el orçamento participativo o presupuestos participativos. En una ciudad con más de un millón y medio de habitantes y grandes bolsas de pobreza los presupuestos participativos supusieron un reto tanto de organización de la población como de puesta en marcha de las peticiones manifestadas por la misma. La ciudad se dividió en 16 zonas para organizar la participación de la población, se crearon organizaciones de participación dedicadas a temas específicos (mujer, sanidad, cultura, etc.), se comenzaron a realizar un mínimo de tres grandes asambleas anuales generales, más las específicas, se establecieron procedimientos para la elección de delegados de las asambleas que las representarían ante la administración, se organizaron organismos intermedios de coordinación y control y se ordenó el proceso de selección de prioridades por las asambleas. En ningún momento fue un proceso improvisado, sino altamente organizado. El nivel de inversión alcanzó el $25 \%$ de la partida municipal dedicada a obras e inversiones y los resultados fueron muy llamativos, especialmente en las zonas pobres de la ciudad: ampliación del suministro de agua potable, mejora del alcantarillado, del asfaltado urbano, del alumbrado público, etc. ${ }^{60}$ No obstante y más allá de los resultados materiales, del caso brasileño tal vez lo más destacable fuera el aumento de participación e implicación ciudadana que los presupuestos participativos

\footnotetext{
59 RAMÍREZ NÁRDIZ, A. (2012): op. cit., p. 114.

${ }^{60}$ RAMÍREZ NÁRDIZ, A. (2012): op. cit., pp. 40-46.
} 
supusieron en una ciudad caracterizada por tener un gran número de ciudadanos en situación de marginación y desconexión social:

«En 1989 el nuevo procedimiento sólo logró una modesta participación popular. En 1990 la participación se mantuvo limitada, en particular por las dificultades de financiación que el Ayuntamiento atravesaba. Pero a partir de ese momento, y gracias a que la ciudad recuperó su capacidad de inversión debido a una profunda reforma fiscal, el presupuesto participativo recibió un fuerte impulso. Desde 1991 los presupuestos participativos empezaron a movilizar a las comunidades de todos los barrios. En 1994 más de 11.000 personas, y en 1995 más de 14.000, acudieron a los encuentros y asambleas regionales dirigidas por el Ayuntamiento. En 1996 unas 100.000 personas asistieron a las distintas asambleas, lo que entonces equivalía al $8 \%$ de la población. A esta participación se debe añadir el gran número de asociaciones locales y organizaciones populares que tomaron parte en los presupuestos participativos.» ${ }^{61}$.

Los efectos de los presupuestos participativos en el Estado de Kerala, en la India, con sus más de 30 millones de habitantes resultan no menos llamativos. En 1996, y tras la victoria electoral del Frente Democrático de Izquierda, se puso en marcha la Campaña de Planificación Popular (People's Plan Campaign o PPC) mediante la cual se comenzó a dedicar entre el 35\% y el $40 \%$ del presupuesto a planes e iniciativas elaborados por los gobiernos locales en cooperación con los ciudadanos mediante procedimientos participativos. Al igual que en el ejemplo brasileño, el proceso participativo keralí no se improvisó o se puso en práctica de modo desorganizado, sino que, por el contrario, se realizó sirviéndose de una organización pormenorizada cuyo objeto era que la voluntad de los ciudadanos se tradujera en actuaciones concretas. Así, se organizaron asambleas, para identificar las necesidades locales, se elaboraron estudios sobre los recursos disponibles, se redactaron informes que se debatieron en seminarios a los que asistían delegados de las asambleas, se formularon en proyectos las necesidades que era factible ejecutar participando en esta formulación funcionarios, representantes electos, expertos y activistas, etc. Toda una serie de puntos intermedios con más de un año de duración hasta la toma de la decisión final. Del modelo keralí, más allá de los beneficios materiales (alcantarillado, potabilización de agua, alumbrado público, etc.) alcanzados para los grupos sociales más necesitados, es de destacar la formación y educación que grandes grupos poblacionales de dicho estado de la India recibieron para poder tomar parte en los presupuestos participativos:

«Unos cien mil voluntarios recibieron formación para dar soporte organizativo a la campaña. El elemento formativo es especialmente importante en

${ }^{61}$ RAMÍREZ NÁRDIZ, A. (2009a): op. cit., p. 133. 
la experiencia keralí, pues desde el primer momento se intentó salvar el vacío existente entre los deseos democráticos participativos y la especialización mínima necesaria para poder ejercer adecuada y productivamente dicha participación. En Kerala se llevó a la práctica un programa de formación masiva que duró varios años y gracias al cual miles de ciudadanos keralíes recibieron algún tipo de formación y educación relativa a cómo organizar y dirigir una reunión, cómo reunir los datos de los pueblos y recopilar los recursos para los mapas, etc. Un ejemplo particularmente esclarecedor de este proceso formativo lo protagonizaron veinticinco mujeres de Chempilode que aprendieron cómo realizar un estudio sanitario adecuado» ${ }^{62}$.

Si Porto Alegre y Kerala son ejemplos de presupuestos participativos en países en vías de desarrollo que afectan a poblaciones de millones o decenas de millones de personas, el caso de San Juan de Alicante con sus poco más de veinte mil habitantes es de interés por comprobar cómo, en comunidades en las que la búsqueda de la satisfacción de las necesidades más básicas que movían a participar a los ciudadanos de Brasil o la India están ya satisfechas, el aumento de la participación ciudadana también es beneficiosa para mejorar la convivencia ciudadana y profundizar en la calidad democrática. Los presupuestos participativos de San Juan empezaron en 2005 y suponían un proceso que se extendía a lo largo de todo el año con la división de la localidad en sectores, la realización de asambleas en cada uno de ellos, la presentación de propuestas por los vecinos, la elección de representantes vecinales que se reunían con técnicos y cargos electos municipales, la priorización de propuestas para su realización por el ayuntamiento previa elaboración de informes y estudio de las necesidades del municipio, etc. Los vecinos pedían cosas tan sencillas como una farola en su calle o mayor limpieza en su barrio y, posiblemente, sólo con ser escuchados y tenidos en cuenta (independientemente de que después se pudiera o no darles esa farola o esa mayor limpieza) se sentían más implicados y comprometidos con su comunidad. Del ejemplo de San Juan de Alicante resulta remarcable la participación en las asambleas ciudadanas de un relevante número de vecinos que, gracias a ellas, pudieron relacionarse de un modo mucho más activo que anteriormente:

«En 2005 asistieron 213 personas a las asambleas (19 en la zona 1, 20 en la zona 2, 96 en la zona 3 y 78 en la zona 4) con una media de edad de 50 años, 115 fueron mujeres y 98 hombres. Se presentaron 577 propuestas, mayoritaria-

62 RAMíreZ NÁRDIZ, A. (2009b): Democracia Participativa. La experiencia española contemporánea, Repositorio institucional de la Universidad de Alicante, pp. 251-257, citando a THOMAS ISAAC, T.M. y W. FRANKE, R. (2004): Democracia local y desarrollo. Campaña popular de planificación descentralizada de Kerala, Játiva, Diálogos L'Ullal Edicions. 
mente por mujeres, y se propusieron como agentes vecinales 42 personas, siendo también mayoritario el número de mujeres.» ${ }^{63}$

Estos tres ejemplos de un mismo instrumento participativo muestran cómo la democracia participativa puede ser especialmente útil para mejorar la convivencia democrática, luchar contra la crisis de la representación y profundizar en la democracia, por muy diferentes que sean las circunstancias y peculiaridades de las distintas sociedades en las que se aplique. Evidentemente, la democracia participativa por sí sola no es la solución a la crisis de la representación. Resulta y puede resultar de gran utilidad para contribuir a revertir el proceso (o, al menos, los efectos de éste, pues las causas últimas que laten tras él son de una complejidad y diversidad que excede el ámbito participativo), pues, si la crisis de la representación implica un alejamiento de los ciudadanos de su gobierno, de sus instituciones y, en definitiva, de la democracia como sistema de gobierno, la democracia participativa tiene por finalidad, precisamente, acercar a los ciudadanos a dicho sistema de gobierno ${ }^{64}$, profundizar en él y hacer que los ciudadanos, más que como un modelo político ajeno a su cotidianeidad e intereses personales, tengan a la democracia por algo propio, un bien personal de cada uno de ellos a título individual y de todos como sociedad.

\section{CONCLUSIONES}

Es posible actuar ante la problemática generada por la crisis de la representación mediante la puesta en práctica y desarrollo de los distintos instrumentos que componen la democracia participativa. La democracia participativa no es, ni podrá ser, en ningún caso, una solución única o exclusiva a la crisis de la representación, pero sí puede contribuir a corregir las manifestaciones más recientes de la misma facilitando que los ciudadanos establezcan vínculos más intensos con la vida pública y con la participación política, así como que consideren la democracia no como un bien colectivo y, en gran medida, ajeno, sino como un bien situado en su esfera personal y, por ello, valioso. ¿Puede la democracia participativa corregir los efectos de la crisis de la representación y la desafección consecuente entre ciudadanos y poderes públicos? No por sí sola. Pero sí puede cooperar en ello. Los instrumentos de los que se compone buscan precisamente

\footnotetext{
63 RAMÍREZ NÁRDIZ, A. (2009a): op. cit., pp. 127-144.

64 «Nada habría que objetar, desde la más elemental lógica democrática, que ante el desolador espectáculo de una ciudadanía en fuga del cumplimiento de sus deberes políticos, se pondere y se estimule la participación.» VEGA, P. de, (1998): op. cit., p. 30.
} 
el acercamiento de los ciudadanos a la vida pública ${ }^{65}$, siendo la desconexión entre dichos dos elementos (ciudadanos y vida pública) la consecuencia más llamativa de la crisis de la representación. En este sentido, la democracia participativa puede ayudar a corregir algunos de los efectos más palpables de la crisis de la representación; más que probablemente no sea bastante para solucionar el problema en su raíz, pero si para contribuir a corregir los efectos por él causados. Así, si un efecto es la desconexión y menor participación de los ciudadanos en la vida pública, la práctica de instrumentos participativos puede contribuir a aumentar dicha participación, pues, evidentemente, si se convocan, por ejemplo, unos presupuestos participativos siempre irán más ciudadanos a las asambleas de los mismos que si no se convocan ${ }^{66}$.

Que esta participación sea lo suficientemente elevada y sostenida en el tiempo como para suponer un freno a los efectos de la crisis de la representación dependerá de múltiples factores que irán desde el modo y forma en que se materialicen los instrumentos participativos, hasta las propias circunstancias de la comunidad — localidad, región, país — en la que se lleven a cabo los mismos. Pero, en todo caso, su realización siempre contribuirá (más que su no realización) al acercamiento de los ciudadanos a su gobierno y, derivado de ello, a que haya más posibilidades de que se produzca una mejora de la visión de aquellos sobre éste y una mejor valoración del modelo político que les gobierna. No parece prudente dar por descontado que el modelo de democracia representativa existente en la actualidad no tiene retorno, es ya para siempre y no está sometido a riesgos de degeneración. Estos riesgos pueden materializarse y, si se valora la democracia representativa como modelo de gobierno, resulta de gran importan-

65 «incorporar instrumentos de participación directa, que permitan ir "de una democracia de espectadores a una democracia de actores”», ACOSTA SÁNCHEZ, J. (1994): op. cit., p. 138. citando a STEFANIA DE SETA, «Da una democrazia di spettatori a una democrazia di attori», La democrazia, utopia o realtá?, pp. 269-271.

${ }^{66}$ En contra de lo que pueda sostenerse por autores como Lipset, Riesman o Janowitz, que consideran que el que se produzca una baja participación ciudadana en las sucesivas convocatorias electorales es síntoma de una deseable estabilidad y buena salud democrática (AGUIAR DE LUQUE, L. y SÁNCHEZ MORÓN, M. en ALZAGA VILLAAMIL, Ó. (1985): Comentarios a las Leyes Políticas. Constitución Española de 1978, tomo II, Revista de Derecho Privado, Editoriales de Derecho Reunidas, Madrid, p. 657), parece cuando menos más afín a la naturaleza, y hasta a la propia etimología, de la democracia considerar que a mayor participación, mayor democracia, pues, en palabras de Bobbio, una definición mínima de democracia la tendría por «un conjunto de reglas procesales para la toma de decisiones colectivas en el que está prevista y propiciada la más amplia participación posible de los interesados.» BOBBIO, N. (1986): op. cit., p. 9. 
cia prever dicha posibilidad y elaborar o, al menos, plantear posibles soluciones, ya sean totales o, como en el caso de la democracia participativa, parciales $^{67}$.

\section{BIBLIOGRAFÍA}

ACOSTA SÁNCHEZ, J. (1994): «La articulación entre representación, Constitución y democracia: Génesis, crisis actual y Constitución española», Revista de Estudios Políticos, n. ${ }^{\circ}$ 86, pp. 99-152.

AGUIAR DE LUQUE, L. y SÁNCHEZ MORÓN, M. EN ALZAGA VILLAAMIL, Ó. (1985): Comentarios a las Leyes Políticas. Constitución Española de 1978, tomo II, Revista de Derecho Privado, Editoriales de Derecho Reunidas, Madrid.

ARAGÓN REYES, M. (2008): «Democracia y Parlamento», Revista Catalana de Dret Públic, n. ${ }^{\circ}$ 37, Generalitat de Catalunya, Escola d'administració pública de Catalunya, pp. 129-155.

ARAGÓN REYES, M. (1996): «Parlamentarismo y antiparlamentarismo en el primer tercio del siglo xx: la proyección actual de aquella polémica», Revista de Estudios Políticos, n. ${ }^{\circ}$ 93, julio-septiembre, pp. 57-66.

ASENSI SABATER, J. (2013): «Partidos en la picota», Diario Información de Alicante, 21 de enero.

- (1998): La época constitucional, Tirant lo Blanch, Valencia.

BOBBIO, N. (1986): El futuro de la democracia, México D. F., Fondo de Cultura Económica.

CONSTANT, B. (1989): «De la libertad de los Antiguos comparada con la de los Modernos», Escritos políticos, Madrid, Centro de Estudios Constitucionales.

FERNÁNDEZ-MIRANDA CAMPOAMOR, C. y FERNÁNDEZ-MIRANDA CAMPOAMOR, A. (2003): Sistema electoral, partidos políticos y parlamento, Madrid, Colex.

FINKIELKRAUT, A. (1982): La nueva derecha norteamericana. La revancha y la utopía, Barcelona, Anagrama.

GARZÓN VALDÉS, E. (1989): «Representación y Democracia», Doxa: Cuadernos de Filosofía del Derecho, Universidad de Alicante, n. ${ }^{\circ}$ 6, pp. 143-164.

JÁUREGUI BERECIARTU, G. (1998): «Democracia: ¿declive temporal u ocaso definitivo?», Revista Internacional de Filosofía Política, n. ${ }^{\circ} 11$, pp. 102-126.

67 «La decadencia de los procesos de deliberación públicos, la segmentación de la política en compartimentos funcionales aislados, y la injusticia derivada de los acuerdos monopolizadores de las minorías corporativas convierten la necesidad de recuperar la participación ciudadana en un asunto que afecta a la dignidad de la esfera política, y, por tanto, a la propia supervivencia de la democracia.» JÁUREGUI BERECIARTU, G. (1998): «Democracia: ¿declive temporal u ocaso definitivo?», Revista Internacional de Filosofía Política, n. ${ }^{\circ} 11$, p. 124. 
HABERMAS, J. (1998): Facticidad y validez. Sobre el derecho y el Estado democrático de derecho en términos de teoría del discurso, Madrid, Trotta.

KORNBLITH, M. (2007): Democracia Directa y Revocatoria de Mandato en Venezuela, Buenos Aires, International IDEA.

KELSEN, H. (1977): Esencia y valor de la democracia, Madrid, Guadarrama, Colección Punto Omega.

LISSIDINI, A. (2008): La democracia directa en Venezuela: ¿democracia participativa o democracia plebiscitaria?, Zurich, C2D.

LUCIANI, M. (2008): «El referéndum. Cuestiones teóricas y de la experiencia italiana», Revista Catalana de Dret Públic, n. ${ }^{\circ} 37$, pp. 157-182.

MONTERO, D.: La Casta: El increíble chollo de ser político en España, La Esfera de los Libros, Madrid, 2009.

PRESNO LINERA, M. A. (2012): «El 15M y la democracia real», El Cronista del Estado Social y Democrático de Derecho, n. ${ }^{\circ} 25$, pp. 38-49.

RAMÍREZ NÁRDIZ, A. (2012): Guía Práctica de la Democracia Participativa. Conocer la Democracia Participativa y aprender a usarla, Madrid, Dykinson.

- (2010): Democracia Participativa. La Democracia Participativa como profundización en la Democracia, Valencia, Tirant lo Blanch.

- (2009A): «Los presupuestos participativos como instrumento de democracia participativa. La experiencia de San Juan de Alicante», Cuadernos Constitucionales de la Cátedra Fadrique Furió Ceriol, n. ${ }^{\circ}$ 66, Universidad de Valencia, pp. 127-144.

- (2009B): Democracia Participativa. La experiencia española contemporánea, Repositorio institucional de la Universidad de Alicante.

RUBIO NÚÑEZ, R. (2007): «La guerra de las democracias», Asamblea: revista parlamentaria de la Asamblea de Madrid, n. ${ }^{\circ}$ 16, pp. 79-107.

SARTORI, G. (1999): «En defensa de la representación política», Claves de razón práctica, n. ${ }^{\circ}$ 91, pp. 2-6.

SCHUMPETER, J. A. (1971): Capitalismo, Socialismo y Democracia, Madrid, Aguilar.

THOMAS ISAAC, T. M. y W. FRANKE, R. (2004): Democracia local y desarrollo. Campaña popular de planificación descentralizada de Kerala, Játiva, Diálogos L'Ullal Edicions.

TOURAINE, A. (1994): ¿Qué es la Democracia?, Madrid, Temas de Hoy.

VEGA, P. DE (1998): Legitimidad y representación en la crisis de la democracia actual, Barcelona, Colección Working Papers, N. ${ }^{\circ}$ 141, Institut de Ciències Polítiques i Socials.

- (1993): «La crisis de la representación política en la democracia de partidos», Tendencias contemporáneas del Derecho electoral en el mundo, México, D. F., Cámara de Diputados, pp. 181-204. 


\section{JURISPRUDENCIA}

- STC 103/2008, DE 11 DE SEPTIEMBRE, FJ 2. ${ }^{\circ}$

- STC 119/1995, DE 17 DE JULIO, FJ 3. ${ }^{\circ} \mathrm{Y} 4 .^{\circ}$

\section{PÁGINAS WEB}

- Cis, Barómetro de noviembre 2013, Estudio n. ${ }^{\circ} 3005$, cis.es, consultado el 02/02/2014.

- Cis, Barómetro de noviembre 2012, Estudio n. ${ }^{\circ}$ 2966, cis.es, consultado el 17/01/2013.

- Democracia real ya, democraciarealya.es, consultado el 09/01/2013.

- Movimiento i 5M (blog), movimiento15m.org, consultado el 09/01/2013.

Title:

THE PARTICIPATION AS ANSWER TO THE REPRESANTATION CRISIS: THE ROLE OF THE PARTICIPATORY DEMOCRACY

\section{Summary:}

I. Brief approach to the concept of representation crisis: 1. Origin of the question; 2. Current approaches: the generalized critic of political parties. II. The role of participatory democracy: 1. What is participatory democracy?; 2. Participatory democracy as response to representation crisis. III. Conclusions. IV. Bibliography. VI. Jurisprudence. VII. Web pages.

\section{Resumen:}

El recurrente debate sobre la crisis de la representación, posiblemente tan antiguo como la representación misma, adquiere en el presente especial relevancia alrededor de la crítica a los partidos políticos y a su rol en la democracia. Si bien el debate y la crítica no son nuevos, sí que lo es la virulencia con la que en el presente se culpa a los partidos políticos de gran parte de los problemas del modelo democrático, si no de todos, así como, particularmente, de suponer un freno al desarrollo del mismo, constituyéndose incluso en un instrumento para su degeneración. Con la finalidad de una hipotética regeneración democrática, una de las demandas más habituales es la de una mayor participación política de los ciudadanos en los asuntos públicos, así como una mejor y más desarrollada fiscalización y control de la acción 
de sus gobernantes. En este sentido, conocer la democracia participativa, entendida como el conjunto de instrumentos participativos que permiten dicha mayor participación de los ciudadanos en los asuntos públicos, sus elementos más característicos, sus posibilidades, pero también sus carencias, así como sus potenciales utilidades para, en su caso, contribuir no sólo a la regeneración democrática, sino también a la mejora de la democracia, resulta de especial interés en el actual escenario de intensa crítica a la democracia representativa. ¿Puede la democracia participativa ser una herramienta verdaderamente útil para la profundización de la democracia? Y, si es así, ¿hay que entenderla como un complemento de la democracia representativa o podría vérsela incluso como una auténtica transformación del modelo democrático? ¿Puede, en definitiva, la democracia participativa, tal y como en el presente se la concibe, ser una respuesta a la crisis de la representación o no es más que la actualización de las fórmulas de democracia directa o semi-directa propias de épocas anteriores y tan habitualmente acusadas de ser susceptibles de usos populistas? Contribuir a responder estar preguntas aportando posibles respuestas a las mismas es el objeto de este artículo.

\section{Abstract:}

The recurring debate on representation crisis, possibly as old as representation itself, has in the present special relevance around the critic of the political parties and its role on democracy. Although the debate and the critic are not new, it is indeed the virulence with which the parties are blamed of a big part of the problems of the democratic system if not of all of them, particularly of being an obstacle to the democratic development, or even a tool for its degeneration. With the finality of an hypothetical regeneration of the democratic system, one of the most typical demands is a bigger political participation of the citizens on public affairs as well as a better and more developed auditing and control of their governors action. In this sense, to know participatory democracy, understood as the set of participatory tools that allow that bigger participation of citizens on public affairs, its most characteristic elements, its possibilities, but also its lacks, as well as its potential utilities for, where appropriate, to contribute not only to the democratic regeneration but also to the improvement of the democracy, has an special interest in the present scenario of intense critic to the representative democracy. Can participatory democracy be a really useful tool for democracy's deepening? And, if that is true, must be understood as a complement to representative democracy or could be seen even as a real transformation of the democratic model? 
Can, in the end, participatory democracy, as is understood in the present, be an answer to the representation crisis or it is nothing but an actualization of the direct democracy or semi-direct democracy formulas typical of old times and so normally accused of being susceptible of populist uses? To contribute to answer these questions giving possible answers to them is the object of this paper.

\section{Palabras clave:}

Democracia participativa, crisis de la representación, respuesta, participación, partidos políticos.

\section{Key words:}

Participatory democracy, representation crisis, answer, participation, political parties. 
